\title{
Physico-Chemical and Thermal Characterization of Alkali-Soluble Lignins from Wheat Straw
}

\author{
Runcang SUN ${ }^{\dagger}$, Jinamin FANG, and Paula Rowlands \\ The BioComposites Centre, University of Wales, Bangor, Gwynedd, LL57 2UW, U.K.
}

(Received August 18, 1997)

\begin{abstract}
Four alkali-soluble lignin fractions were extracted from dewaxed wheat straw with 3\% sodium hydroxide at $45^{\circ} \mathrm{C}$ for $2,5,12$, and $15 \mathrm{~h}$, respectively. The pure alkali-soluble lignin preparations LA were obtained by using a two step precipitation method instead of the traditional ether precipitation procedure. The physico-chemical properties and structural features of the isolated pure lignin fractions were characterized by UV, FT-IR, ${ }^{13} \mathrm{C}$ NMR spectroscopy, and thermal analysis. The lignin in fraction LA- 1 is mainly composed of $\beta-O-4$ ether bonds. The less common $\beta-5$ and $\beta-\beta$ carbon-carbon linkages are also present in the lignin structural units. The results obtained showed that the lignin fractions appeared to be strongly associated to hydroxycinnamic acids such as $p$-coumaric and ferulic acids and glucuronic acid or 4- $O$-methylglucuronic acid.

KEY WORDS Wheat Straw / Lignin / Polysaccharides / Nitrobenzene Oxidation / ${ }^{13} \mathrm{C}$ Nuclear Magnetic Resonance / Thermal Study / Molecular Weight /
\end{abstract}

Lignin is a phenolic polymer built up by oxidative coupling of three major $\mathrm{C}_{6}-\mathrm{C}_{3}$ (phenylpropanoid) units, trans-p-coumaryl alcohol $(\mathrm{H})$, guaiacyl (coniferyl) alcohol (G), and syringyl (sinapyl) alcohol (S), which form a randomized structure in a tridimensional network inside the cell wall. The major interunit linkage is an aryl-aryl ether type. ${ }^{1}$ The straw lignins (GSH-lignin) are known to be different from those of softwoods (G-lignin) or hardwoods (GS-lignin). Furthermore, straw and grass cell walls are typified by the presence ferulic and $p$ coumaric acids, linked to polysaccharides and/or lignin. It has been identified that $p$-coumaric acid is linked to lignin via ester or ether bonds while ferulic acid constitutes a bridge binding to polysaccharides via ester bonds and to lignin via ether bonds. ${ }^{2}$ Obviously, such cross-linking has been regarded to have a dramatic influence on the physico-chemical properties of straw and grass lignins. ${ }^{3}$ One of the most striking properties is that straw lignin has a high solubility in alkaline solution. Several recent publications have reported that $60-70 \%$ of the lignin from wheat straw is extracted with dilute alkali at temperature below $100^{\circ} \mathrm{C}$, even at room temperature. In woody materials such as pine and birch, however, these percentages reach only about 20 or $30 \%$, respectively. ${ }^{4}$ Mild alkaline treatment is not prone to cause much chemical modification beyond the saponification of ester bonds between $p$-coumaric acid and lignin or ferulic acid and polysaccharides. Surprisingly, the alkali lignins have only rarely been utilized for the structural studies of straw and grass lignins. The main reasons for this rare application of alkali lignin for structural characterization of straw lignins are the limitations of present isolation and purification methodologies. The alkali lignins, purified by traditional ether precipitation, contain much higher amounts of non lignin materials such as polysaccharides, and cause losses of ether-soluble lignin. We have proposed a alternative two step precipitation method to traditional ether precipitation procedures for the isolation and purification of alkali, ball milling, and enzyme lignins with relatively

\footnotetext{
† To whom correspondence should be addressed.
}

free associated polysaccharides from wheat straw, oil palm trunks, abaca fibre, and sugar-beet pulps.

The present study describes physico-chemical and thermal characterizations of the alkali-soluble lignin fractions, extracted on a large scale with $3 \% \mathrm{NaOH}$ at $45^{\circ} \mathrm{C}$ for $2,5,12$, and $15 \mathrm{~h}$, respectively, and purified by a two step precipitation method. A comparative study of the isolated alkali lignins with the lignin fractions extracted on a small scale is also reported.

\section{MATERIALS AND METHODS}

\section{Materials}

The wheat straw was obtained from Compak Co. (Gainsborough, England). The air-dried wheat straw was ground using a Christie Laboratory mill to pass a 60 mesh size screen. The ground straw was then extracted with chloroform-methanol $(2: 1, \mathrm{v} / \mathrm{v})$ at $45^{\circ} \mathrm{C}$ for $6 \mathrm{~h}$ (for alkali lignin fraction 1), toluene-ethanol $(2: 1, \mathrm{v} / \mathrm{v})$ at $45^{\circ} \mathrm{C}$ for $12 \mathrm{~h}$ (for alkali lignin fraction 2), and tolueneethanol $(2: 1, \mathrm{v} / \mathrm{v})$ in a Soxhlet for $6 \mathrm{~h}$ (for alkali lignin fractions 3 and 4$)$.

\section{Isolation of Alkali Lignin Fractions}

The extractive-free straw $(150-500 \mathrm{~g})$ was treated with $3 \% \mathrm{NaOH}(4-13.3 \mathrm{~L})$ at $45^{\circ} \mathrm{C}$ for $2,5,12$, and $15 \mathrm{~h}$, respectively under continuous agitation conditions. The hemicellulose-lignin complexes were removed by precipitation of the neutralized hydrolysate in 4 vols of ethanol. The alkali-soluble lignins LA were then precipitated at $\mathrm{pH} 1.5$ with $20 \% \mathrm{HCl}$ from the supernatant solution and washed with acidified water ( $\mathrm{pH} 2.0)$ (Figure 1). The air-dried alkali lignins were labelled as fractions LA-1, LA-2, LA-3, and LA-4, and kept in a refrigerator at $5^{\circ} \mathrm{C}$ until analysis.

\section{Physico-Chemical and Thermal Characterization of Lignin Fractions}

UV spectra were recorded on a Hewlett-Packard 8452A Diode Array spectrophotometer. Lignin sample $(5 \mathrm{mg})$ was dissolved in $95 \%(\mathrm{v} / \mathrm{v})$ dioxane-water $(10$ $\mathrm{mL}$ ). A $1 \mathrm{~mL}$ aliquot was diluted to $10 \mathrm{~mL}$ with $50 \%$ 
(v/v) dioxane-water, and the absorbances between 200 and $350 \mathrm{~nm}$ were measured.

The molecular-average weights of lignin fractions were determined by gel permeation chromatography on a PLgel $5 \mu$ Mixed-D column. The samples were dissolved in tetrahydrofuran at a concentration of $0.2 \%$, and a $200 \mu \mathrm{L}$ sample in solution was injected. The columns were operated at $40^{\circ} \mathrm{C}$ and eluted with tetrahydrofuran at a flow rate of $1 \mathrm{~mL} \mathrm{~min}{ }^{-1}$. The column was calibrated using polystyrene standards.

FT-IR spectra were obtained on an FT-IR spectrophotometer (Nicolet, 750) using a $\mathrm{KBr}$ disc containing $1 \%$ finely ground samples. The solution-state ${ }^{13} \mathrm{C} \mathrm{NMR}$ spectra were obtained on a Bruker $250 \mathrm{AC}$ spectrometer operating in the FT mode at $62.4 \mathrm{MHz}$ under total proton decoupled conditions. They are recorded at $25^{\circ} \mathrm{C}$ from $250 \mathrm{mg}$ of sample dissolved in $1.0 \mathrm{~mL} \mathrm{DMSO}-d_{6}$ after 30000 scans. A $40^{\circ}$ pulse flipping angle, a $3.0 \mu$ s pulse width and $0.85 \mathrm{~s}$ acquisition time were used.

Thermographic analysis of lignin fractions was performed with a Thermogravimetric Analyser (PL-Thermal Sciences). This apparatus provides for a continuous measurement of sample weight at a range of temperatures between ambient and $600^{\circ} \mathrm{C}$. Samples of approximately $10 \mathrm{mg}$ were heated in a platinum crucible to $600^{\circ} \mathrm{C}$ at a heating rate of $10^{\circ} \mathrm{Cmin}^{-1}$. The provision was made for electronic differentiation of the weight signal to give the rate of weight loss. Air was used as the purge gas, and positive pressure was maintained within the weighing chamber in order to protect the balance mechanism from the condensables formed during pyrolysis.

Alkaline nitrobenzene oxidation of lignin was performed at $170^{\circ} \mathrm{C}$ for $3 \mathrm{~h}$, with $3.5 \% O$-phenanthroline as a catalyst. Neutral sugar composition in isolated lignin fractions was determined as alditol acetates. ${ }^{5}$

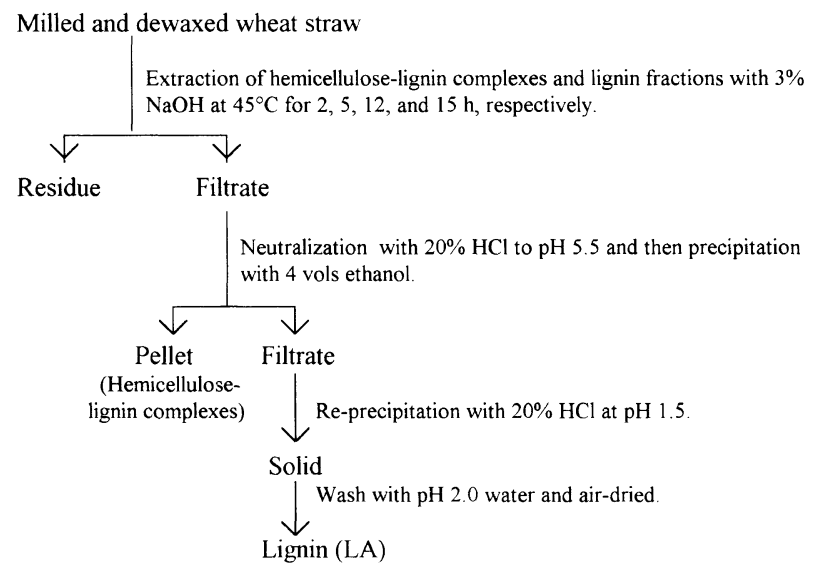

Figure 1. Scheme for isolation of alkali-soluble lignin fractions from wheat straw.
Methods of uronic acid analyses and determination of phenolic acids and aldehydes with HPLC in nitrobenzene oxidation mixtures have been described in previous papers. ${ }^{3,6}$ All nitrobenzene oxidation results represent the mean of at least triplicate samples and each oxidation mixture was chromatographed twice. Other experiments were performed in duplicate.

\section{RESULTS AND DISCUSSION}

\section{Lignin Yield}

The yields of alkali lignins resulting from the fractionation procedures were expressed as a percentage of the total lignin determined by acidic chlorite oxidation (14.1\% by weight).

The total extraction yields of alkali lignins obtained from wheat straw ranged from 54.2 to $70.4 \%$ of the total acidic chlorite lignin with the increase of extraction duration from 2 to $15 \mathrm{~h}$ (Table I), indicating that extension of extraction time tended to favor the lignin dissolution in the alkaline solution. During the alkaline extracting process, some alkali-labile linkages between lignin monomers, or between lignin and polysaccharides, might be broken by alkaline extraction. Acidic moieties such as carboxylic or phenolic groups, ionized in alkaline solution, might also promote the solubilization of the lignin, either by increasing the solubility of individual fragments or by inducing the swelling of the cell wall. ${ }^{3}$ In addition, the participation of ester-linked cinnamic acids, particularly ferulic acids, as linkage bridges between lignin and hemicelluloses in straw and grass is considered to play a role in the high extraction of lignin yields. ${ }^{4}$ As illustrated in Table I, the yields of LA in fractions 1 and 2 were higher than those of LB, while the reverse yields were observed for fractions 3 and 4 . These results suggest that isolation of extractives in chloroform-methanol or toluene-ethanol solution results in a more effective release of lignin from neighboring polysaccharide moieties than the Soxhlet extraction for the next step of alkaline treatment. On comparison with the yields of alkali lignin preparations obtained with $1.5 \%$ sodium hydroxide at $20^{\circ} \mathrm{C}$ for various periods, on a small scale and a high ratio of extractant/straw $(40 \mathrm{~mL}$ extractant $/ 1 \mathrm{~g}$ straw), ${ }^{7}$ the much lower yield ratios (LA/ LB) of pure lignin (LA) to the lignin associated in the solublilized polysaccharide fractions (LB), indicates that a low ratio of extractant/ straw $(27 \mathrm{~mL}$ extractant $/ 1 \mathrm{~g}$ straw), a relatively high concentration of sodium hydroxide $(3 \%)$, and slightly higher temperature $\left(45^{\circ} \mathrm{C}\right)$ might result in lignin condensation and impede the lignin liberation from cell walls.

Table I. The yield (\% acidic chlorite lignin) of alkali-soluble lignins isolated with $3 \% \mathrm{NaOH}$ at $45^{\circ} \mathrm{C}$ for different periods

\begin{tabular}{|c|c|c|c|c|}
\hline Lignin fractions/Extraction conditions & Total & $\mathrm{LA}^{\mathrm{a}}$ & $\mathrm{LB}^{\mathrm{b}}$ & $\mathrm{LA} / \mathrm{LB}$ \\
\hline Fraction $1\left(3 \% \mathrm{NaOH}\right.$ at $45^{\circ} \mathrm{C}$ for $\left.2 \mathrm{~h}\right)$ & 54.2 & 29.5 & 24.7 & 1.2 \\
\hline Fraction $2\left(3 \% \mathrm{NaOH}\right.$ at $45^{\circ} \mathrm{C}$ for $\left.5 \mathrm{~h}\right)$ & 63.3 & 39.5 & 23.8 & 1.7 \\
\hline Fraction $3\left(3 \% \mathrm{NaOH}\right.$ at $45^{\circ} \mathrm{C}$ for $\left.12 \mathrm{~h}\right)$ & 68.8 & 29.4 & 39.4 & 0.8 \\
\hline Fraction $4\left(3 \% \mathrm{NaOH}\right.$ at $45^{\circ} \mathrm{C}$ for $\left.15 \mathrm{~h}\right)$ & 70.4 & 33.3 & 37.1 & 0.9 \\
\hline
\end{tabular}

${ }^{\mathrm{a}}$ Obtained by precipitation of the supernatant solution with $20 \% \mathrm{HCl}$ at $\mathrm{pH} 1.5$ after isolation of hemicellulose-lignin complexes. ${ }^{\mathrm{b}} \mathrm{Coprecipitated}$ in the hemicellulose-lignin complexes. 


\section{UV Spectra}

The four alkali lignin fractions (LA) exhibited the basic UV spectrum typical of lignins, having three absorption maxima at 314,280 , and $230 \mathrm{~nm}$. The spectra of alkali lignin fractions LA-3 and LA-4 are shown in Figure 2. The absorption maximum at $\lambda 280 \mathrm{~nm}$ originates from non-conjugated phenolic groups (aromatic ring), ${ }^{8}$ and the absorption maximum at $\lambda 314 \mathrm{~nm}$ can be attributed to the absorption of the carbonyl moiety in ester bonds. ${ }^{9}$ A slightly higher absorption coefficient in LA-3 fraction than in LA-4 indicates a purer LA-3 lignin fraction than LA-4.

\section{Content of Associated Polysaccharide Sugars and Uronic Acids}

As can be seen in Table II, the four lignin fractions LA, isolated by a two step precipitation method, contain rather low amounts of bound polysaccharides (1.37$2.82 \%$ ). The main reason for is that alkali treatment would be expected to saponify the hydroxycinnamic esters such as between $p$-coumaric acid and lignin or between ferulic acid and hemicelluloses. Xylose and glucose were identified as the only two sugar components. Extension of alkaline treatment time from 2 to $15 \mathrm{~h}$ results in a decrease in the level of associated polysaccharides from 2.82 to $1.37 \%$ in the isolated lignin fractions LA-1 to LA-4, respectively. This phenomenon suggests that an increase in alkaline treatment duration can peel more lignin from most of the neighboring polysaccharide moieties.

Interestingly, as compared to the neutral sugar content, a high content of uronic acids in the four lignin fractions is probably due to the ester bonds between lignin and glucuronic acid or 4-O-methylglucuronic acid residue of hemicelluloses in wheat straw cell walls. Occurrence of the ester bond between lignin and glucuronic acid or 4- $O$-methylglucuronic acid was confirmed by two signals at 60.3 and $174.8 \mathrm{ppm}$ in ${ }^{13} \mathrm{C}$ NMR spectrum.

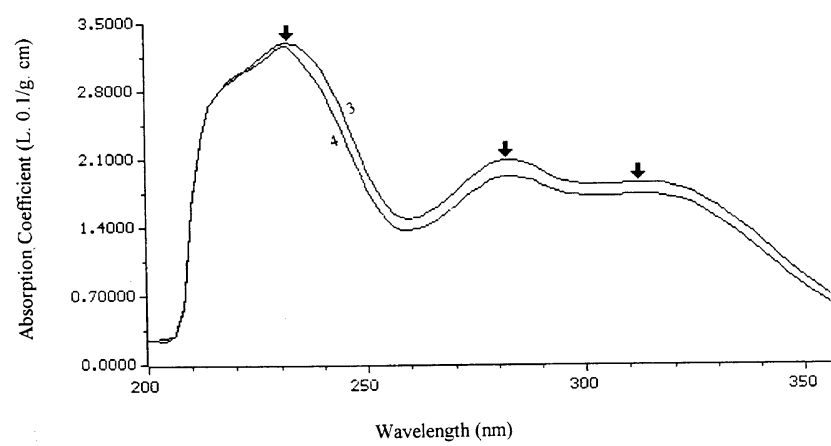

Figure 2. UV spectra of alkali-soluble lignin fractions 3 and 4 extracted with $3 \% \mathrm{NaOH}$ at $45^{\circ} \mathrm{C}$ for 12 and $15 \mathrm{~h}$, respectively.

\section{Content of Phenolic Monomers}

Yields of phenolic acids and aldehydes obtained by nitrobenzene oxidation of the four lignin fractions are given in Table III. These products, acids and aldehydes, resulted from the degradation of non-condensed lignin monomers. Obviously, addition of $3.5 \% \mathrm{O}$-phenanthroline to the nitrobenzene oxidation resulted in $2-3$ times increase in the yield of oxidation products than those observed for the non-catalyst reaction. ${ }^{7}$ This finding was in accordance with the studies of Gogotov and coworkers on the catalysis of alkali nitrobenzene oxidation of wood lignin. ${ }^{10}$ The authors mentioned that the yield of aromatic hydroxyl aldehydes in nitrobenzene oxidation of lignin can be increased significantly by using common catalysts for alkali and oxygen-alkali delignification. The relatively lower yields of oxidation products found in the case of LA-1 and LA- 2 may be explained by a higher degree of condensation in the two lignin fractions.

As can be seen in Table III, the major products were identified as approximately equal amount of vanillin and syringaldehyde, resulting from the degradation of noncondensed guaiacyl and syringyl units, respectively. The molar ratios of vanillin/syringaldehyde in the four lignin oxidation products were $1.28,1.15,1.25$, and 1.10 , respectively. This suggests that non-condensed guaiacyl units are more easily degradable than non-condensed syringyl units in wheat straw cell walls during the alkaline treatments. These results agree with our earlier studies on wheat straw alkali lignins isolated on a small scale. ${ }^{7}$ We indicated that wheat straw alkali lignin contains roughly equal amounts of non-condensed guaiacyl and syringyl units with relatively fewer $p$-hydroxyphenyl units. Occurrence of a low amount of $p$-hydroxybenzaldehyde is due to the non-condensed $p$-hydroxyphenyl unit, indicating the incorporation of $p$-hydroxycinnamoyl alcohol in wheat straw lignin. A relatively high content of ferulic acid and low amount of $p$-coumaric acid in the oxidation mixture of the four lignin fractions suggests that significant amounts of ferulic acids are etherified to lignin, whereas a considerable proportion of $p$-coumaric acid is linked to lignin by ester bonds.

\section{Molecular Weight Distribution}

The weight-average $\left(M_{w}\right)$ and number-average $\left(M_{n}\right)$ molecular weights, and polydispersity $\left(M_{w} / M_{n}\right)$ of each fraction were computed from their chromatograms and are given in Table IV. As can be seen, there is no significant difference in the molecular weight values among the four isolated lignin fractions, indicating that the same degradation or same cleavage of interunit linkages of lignin occurs during the alkaline treatment between 2

Table II. The content ( $\%$ dry weight) of polysaccharide sugars and uronic acids in the isolated lignin fractions

\begin{tabular}{|c|c|c|c|c|c|c|c|c|}
\hline \multirow{2}{*}{ Fraction No. } & \multicolumn{6}{|c|}{ Polysaccharide sugars } & \multirow{2}{*}{$\begin{array}{l}\text { Uronic } \\
\text { acids }\end{array}$} & \multirow{2}{*}{ Tota } \\
\hline & Rha & Ara & Xyl & Man & Glc & Gal & & \\
\hline LA-1 & $\mathrm{N}$ & $\mathbf{N}$ & 0.96 & $\mathrm{~N}$ & 0.24 & $\mathrm{~N}$ & 1.62 & 2.82 \\
\hline LA-2 & $\mathrm{N}$ & $\mathrm{N}$ & 0.28 & $\mathrm{~N}$ & 0.24 & $\mathrm{~N}$ & 1.43 & 1.95 \\
\hline LA-3 & $\mathrm{N}$ & $\mathrm{N}$ & 0.12 & $\mathrm{~N}$ & 0.24 & $\mathrm{~N}$ & 1.21 & 1.57 \\
\hline LA-4 & $\mathrm{N}$ & $\mathrm{N}$ & 0.12 & $\mathrm{~N}$ & 0.24 & $\mathrm{~N}$ & 1.21 & 1.37 \\
\hline
\end{tabular}

$\mathrm{N}=$ not detectable. 
Table III. The yield ( $\%$ sample, $w / w)$ of phenolic acids and aldehydes from alkaline nitrobenzene oxidation of alkali lignin LA isolated from the hydrolysates of alkaline treatment of wheat straw

\begin{tabular}{lrrrr}
\hline \multirow{2}{*}{$\begin{array}{c}\text { Phenolic acids and } \\
\text { aldehydes }\end{array}$} & \multicolumn{5}{c}{ Lignin fractions } \\
\cline { 2 - 5 } & LA-1 & LA-2 & LA-3 & LA- 4 \\
\hline Gallic acid & 0.32 & 0.23 & 0.39 & 0.38 \\
Protocatechuic acid & 0.41 & 0.31 & 0.41 & 0.42 \\
$p$-Hydroxybenzoic acid & 0.79 & 0.51 & 0.53 & 0.77 \\
$p$-Hydroxybenzaldehyde & 1.48 & 2.72 & 2.20 & 3.44 \\
Vanillic acid & 0.72 & 0.61 & 0.44 & 1.03 \\
Syringic acid & 1.29 & 2.36 & 2.90 & 4.04 \\
Vanillin & 16.05 & 18.93 & 26.12 & 25.20 \\
Syringaldehyde & 15.01 & 19.76 & 25.07 & 27.34 \\
$p$-Coumaric acid & 0.38 & 0.77 & 0.21 & 1.05 \\
Ferulic acid & 0.64 & 1.64 & 1.66 & 3.02 \\
\hline Total & 37.09 & 47.84 & 59.93 & 66.69 \\
& & & & \\
\hline
\end{tabular}

Table IV. The weight-average $\left(M_{w}\right)$, number-average $\left(M_{n}\right)$ molecular weights, and the polydispersity $\left(M_{w} / M_{n}\right)$ of the alkali lignin LA isolated from the hydrolysates of alkaline treatment of wheat straw

\begin{tabular}{cccc}
\hline Fraction No. & $\bar{M}_{w}$ & $\bar{M}_{n}$ & $\bar{M}_{w} / \bar{M}_{n}$ \\
\hline LA-1 & 2400 & 1710 & 1.40 \\
LA-2 & 2560 & 1840 & 1.39 \\
LA-3 & 2590 & 1840 & 1.41 \\
LA-4 & 2410 & 1740 & 1.38 \\
\hline
\end{tabular}

and $15 \mathrm{~h}$. The forgoing data also illustrate that extraction of wheat straw with $3 \% \mathrm{NaOH}$ at $45^{\circ} \mathrm{C}$ and isolation by a two step precipitation method results in pure lignin preparations, having higher average molecular weights than the lignin fractions extracted on a small scale with a high ratio of extractant/straw as reported in our previous studies. ${ }^{7}$ The reason for the relatively high molecular weights obtained in this study is undoubtedly due to the lignin condensation at a low ratio of extractant/straw during the large scale extraction processes.

The GPC molecular weight distribution of LA-1 is shown in Figure 3. The elution maximum corresponds to polystyrene molecular weight of 2010 . The elution profile of the lignin shows a wide polymolecularity, ranging from dimers up to polystyrene of molecular weight over 23000 .

\section{FT-IR Spectra}

The FT-IR spectra of the four lignin fractions, LA, show minor changes in the peak intensities (Figure 4), which confirm that the 'core' of the lignin structure does not change dramatically during the different periods of alkaline treatment processes. As shown in Figure 4, the intense polysaccharide bands are not detected, suggesting a relatively low content of associated sugars in the samples. The bands at $1651 \mathrm{~cm}^{-1}$ in LA-1 and $1640 \mathrm{~cm}^{-1}$ in LA-2 have been assigned to carbonyl stretching in conjugation with the aromatic ring, while the bands between $1710-1691 \mathrm{~cm}^{-1}$ have been attributed to carbonyl stretching in unconjugation with the aromatic ring. The very weak peak at $1655 \mathrm{~cm}^{-1}$ in LA-3 and LA4 points to a near disappearance of carbonyl stretch-

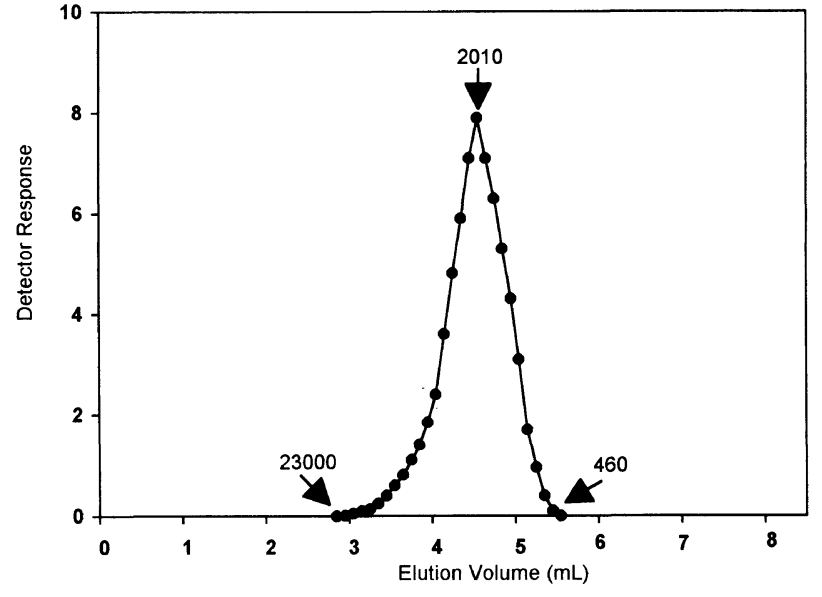

Figure 3. GPC molecular weight distribution of alkali-soluble lignin fraction 2 extracted with $3 \% \mathrm{NaOH}$ at $45^{\circ} \mathrm{C}$ for $5 \mathrm{~h}$ from wheat straw.

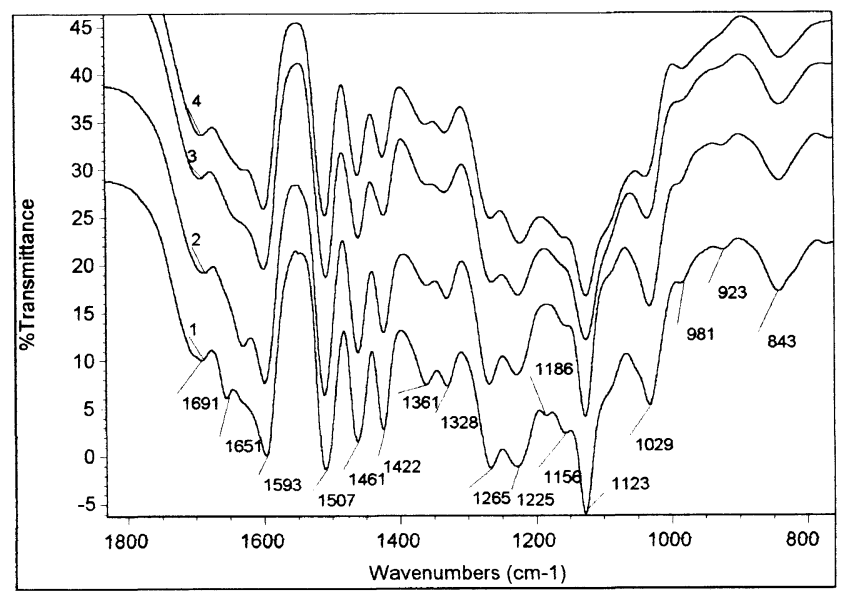

Figure 4. FT-IR spectra of alkali-soluble lignin fractions 1, 2, 3, and 4.

ing in conjugation with aromatic ring during the alkaline treatment between 12 and $15 \mathrm{~h}$. Aromatic skeleton vibrations in the lignin fractions are assigned at 1593, 1507 , and $1422 \mathrm{~cm}^{-1} \cdot{ }^{11}$ Absorption at $1461 \mathrm{~cm}^{-1}$ indicates the $\mathrm{C}-\mathrm{H}$ deformations and aromatic ring vibrations. The 1328,1265 , and $1225 \mathrm{~cm}^{-1}$ bands have been assigned to ring breathing with $\mathrm{C}-\mathrm{O}$ stretch. The $1328 \mathrm{~cm}^{-1}$ band has been associated with sinapyl units, and 1265 and $1225 \mathrm{~cm}^{-1}$ bands with coniferyl units. Two small bands at 1361 and $1156 \mathrm{~cm}^{-1}$ correspond to aliphatic $\mathrm{C}-\mathrm{H}$ stretch in $\mathrm{CH}_{3}$ and $\mathrm{C}=\mathrm{O}$ ester groups (conj.), respectively. The bands at 1123 and $1029 \mathrm{~cm}^{-1}$ indicate the aromatic $\mathrm{CH}$ in-plane deformation. Aromatic $\mathrm{C}-\mathrm{H}$ out of plane bending appears at $843 \mathrm{~cm}^{-1}$.

\section{${ }^{13}$ C NMR Spectrum}

The LA-1 lignin fraction was also studied by ${ }^{13} \mathrm{C}$ NMR spectroscopy (Figure 5). Most of the observed signals have been previously assigned in straw and wood lignin spectra. ${ }^{8,12-17}$ As expected, the most striking characteristic of the ${ }^{13} \mathrm{C}$ NMR spectrum is the near disappearance of typical polysaccharide signals between 57 and 103 ppm. This phenomenon was also observed during our previous studies on wheat straw alkali lignin fractions extracted on a small scale and isolated by a two step precipitation method. ${ }^{7}$ Due to the rather low content of 


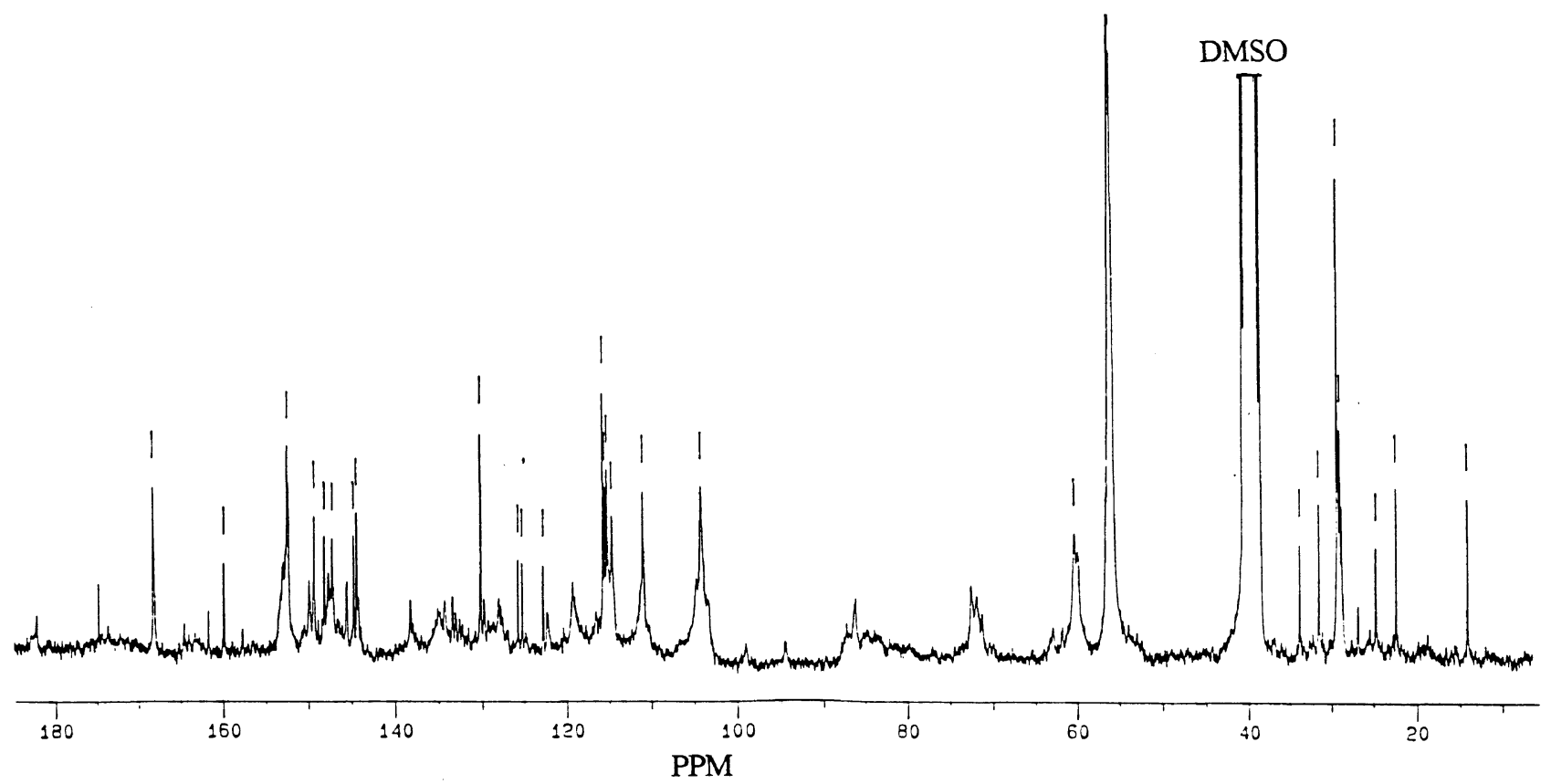

Figure $5{ }^{13} \mathrm{C}$ NMR spectrum of alkali-soluble lignin fraction 1(in DMSO- $d_{6}$ ).

bound polysaccharides in the LA-1 fraction, the spectrum showed only one signal at $63.0 \mathrm{ppm}$ (C-5, xyl. Internal unit) for polysaccharides, and the peak intensity is rather weak.

The region from 104.4 to $160.0 \mathrm{ppm}$ is assigned to the aromatic moiety of the lignin. The syringyl residues are indicated by signals at 152.3 (C-3/C-5, S), 138.1 (C-4, S etherified), 135.0 (C-1, S etherified), 132.8 (C-1, S non etherified), and $104.4 \mathrm{ppm}$ (C-2/ C-6, S), and guaiacyl residues by signals at 149.8 (C-4, $\mathrm{G}$ etherified), 149.2 (C-3, G etherified), 148.1 (C-3, G), 147.2 (C-3, G), 145.3 (C-4, G non etherified), 135.0 (C-1, G etherified), 132.8 (C-1, G non etherified), 119.5 (C-6, G), 114.9 (C-5, G), and $111.2 \mathrm{ppm}(\mathrm{C}-2, \mathrm{G})$, respectively. The $p$-hydroxyphenyl residues are identified by signals at 127.8 and $127.6 \mathrm{ppm}(\mathrm{C}-2 / \mathrm{C}-6, \mathrm{H})$. These signals confirm that the LA-1 lignin fraction could be justified as a GSH-lignin. The signals at 168.2 (C- $\gamma$, PC ester), 159.8 (C-4, PC ester), 144.7 and 144.4 (C- $\alpha$, PC ester), 130.3 (C-2/C-6, PC ester), 125.9 and 125.4 (C-1, PC ester), and 115.9, 115.8 and $115.4 \mathrm{ppm}$ (C-3/C-5, PC ester) indicate the presence of esterified $p$-coumaric acid. Etherified ferulic acid is observed with signals at 168.2 (C- $\gamma$, FE ether) overlapped by the signal for esterified $p$-coumaric acid, 144.1 (C- $\alpha$, FE ether), and 116. 4 ppm (C- $\beta$, FE ether). ${ }^{14}$ Therefore, it seems very likely that the $p$-coumaric acids are linked by ester bonds at the $\gamma$ - and $\alpha$-positions of lignin side chains, while the ferulic acids are linked by ether bonds at the $\beta, \gamma$-, and $\alpha$-positions of lignin side chains.

A very strong signal at $56.0 \mathrm{ppm}$ corresponds to the $\mathrm{OCH}_{3}$ in syringyl and guaiacyl units. The intensive signals assigned to $\gamma$-methyl, $\alpha$ and $\beta$-methylene groups in $n$-propyl side chains appear between 14.1 and 33.8 ppm. The carbonyl resonances from uronic acids and esters may contribute to signals at 174.8 and $60.3 \mathrm{ppm}$. A signal at $174.8 \mathrm{ppm}$ indicates C-6 in methyl uronates $(\mathrm{C}=\mathrm{O}$ in aliphatic acids or esters), and the signal at $60.3 \mathrm{ppm}$ also partially originates from the 4-O-methoxyl group of the glucuronic acid residue in the xylan. ${ }^{16}$. The
${ }^{13} \mathrm{C}$ NMR spectrum also indicates that $\beta-O-4$ linkages $(\mathrm{C}-\alpha$ in $\beta-O-4,72.5 \mathrm{ppm} ; \mathrm{C}-\beta$ in $\beta-O-4,86.1 \mathrm{ppm} ; \mathrm{C}-\gamma$ in $\beta-O-4,60.3 \mathrm{ppm})$ still remain as major ether linkages between the lignin structural units after alkaline treatment. The less common $\beta-\beta(\mathrm{C}-\gamma$ in $\beta-\beta, 71.4 \mathrm{ppm})$ and $\beta-5(\mathrm{C}-\alpha$ in $\beta-5,87.1 \mathrm{ppm})$ carbon-carbon linkages are also present.

\section{Thermogravimetric Analysis}

Typical thermograms for the lignin sample LA-4 are shown in Figure 6 . These thermograms were obtained at a heating rate of $10^{\circ} \mathrm{C} \mathrm{min}^{-1}$ and heating from ambient to a maximum temperature of $600^{\circ} \mathrm{C}$. In thermogravimetry, the losses of weight are due to evolution of water, carbon monoxide, carbon dioxide, and evaporation of other pyrolysis products, and are collectively measured as a percentage of the original weight. The thermogram shows a three-stage decomposition with exothermic peaks at about 260,300 , and $420^{\circ} \mathrm{C}$, respectively. The thermogravimetric curve, as shown in Figure 6, indicates that weight loss begins at $200-210^{\circ} \mathrm{C}$ and proceeds until approximately $490^{\circ} \mathrm{C}$ where the weight of the sample is reduced to almost $10 \%$, probably due to the ash or salt content.

Based on the above studies, it can be concluded that the four alkali lignin fractions LA, obtained by a two step precipitation method, show similar chemical composition and physico-chemical properties. They are relatively free of polysaccharides and contain nearly equal amounts of non-condensed guaiacyl and syringyl units with fewer $p$-hydroxyphenyl units. On comparison of the alkali lignin fractions, obtained on a small scale, and with a high ratio of extractant/straw, with the lignin fractions, extracted on a large scale, and with a low ratio of extractant/straw proposed in this study, higher molecular-average weights $(2400-2590 \mathrm{Da})$ are observed, which suggests that alkali lignin preparations, isolated by this two step precipitation method instead of traditional ether precipitation, may be used for most struc- 


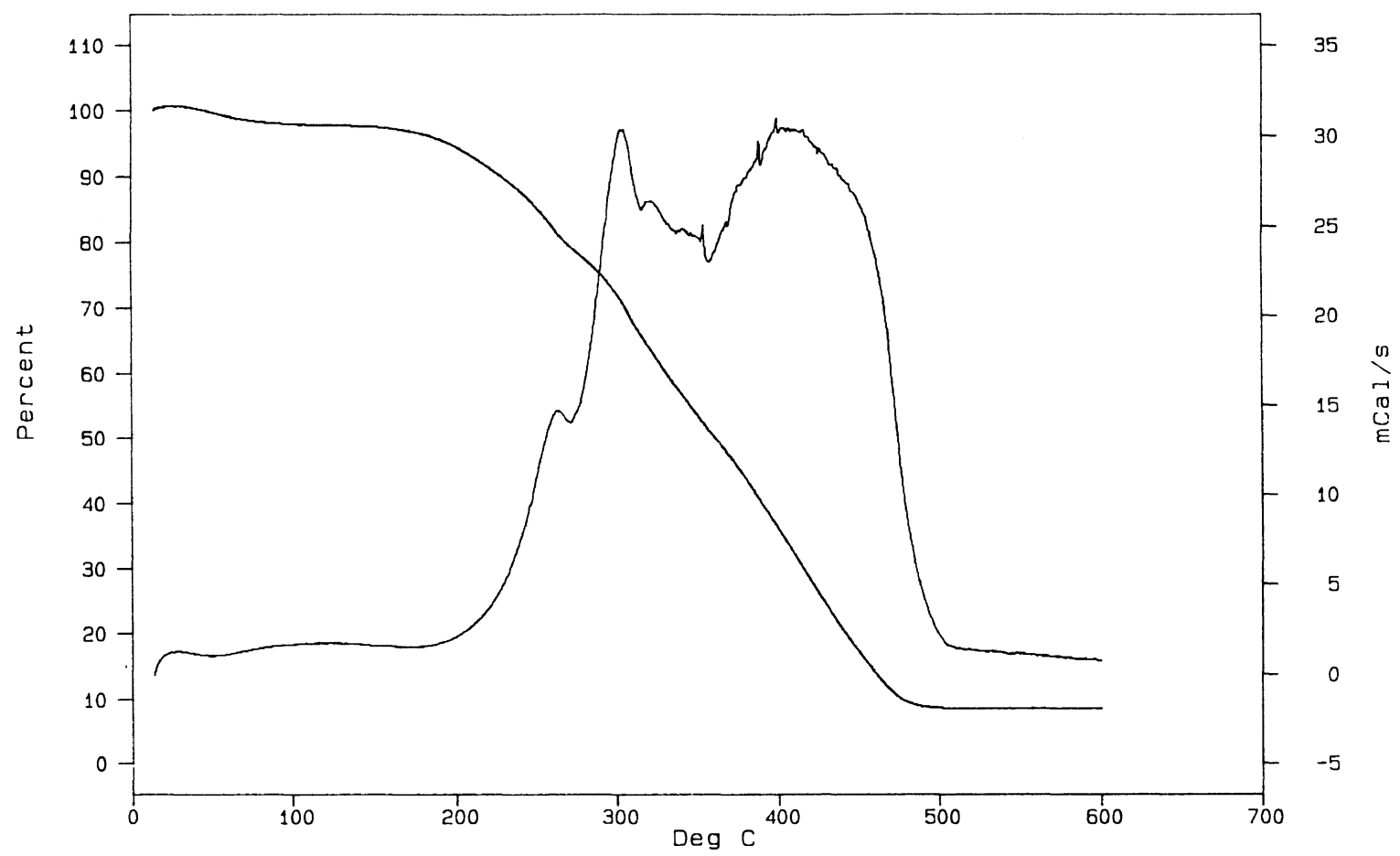

Figure 6. Thermogram of lignin fraction 4 extracted with $3 \% \mathrm{NaOH}$ at $45^{\circ} \mathrm{C}$ for $15 \mathrm{~h}$.

tural studies in lignins from straw and grass.

Acknowledgments. The authors are grateful for the financial support of this research from the European Community under the Industrial \& Materials Technologies Programme (Brite-EuRam III)-Depolymerisation, Polymerisation and Applications of Biosustainable Raw Materials for Industrial End Uses and to Dr. James Bolton, Director of The BioComposites Centre, for the award of a senior research fellowship to Dr. R. C. Sun.

\section{REFERENCES}

1. G. Wallace and S. Fry, Int. Rev. Cytol., 151, 229 (1994).

2. C. Crestini and D. S. Argyropoulos, J. Agric. Food Chem., 45, 1212 (1997).

3. R.-C. Sun, J. M. Lawther, and W. B. Banks, Industrial Crops and Products, 4, 127 (1995).

4. M. C. Terrón, M. L. Fidalgo, G. Almendros, and A. E. Gonzalez, Rapid Commun., Mass Spectrom., 10, 413 (1996).

5. A. B. Blakeney, P. J. Harris, R. J. Henry, and B. A. Stone, Carbohydr. Res., 113, 291 (1983).
6. J. M. Lawther, R.-C. Sun, and W. B. Banks, J. Agric. Food Chem., 43, 667 (1995).

7. R.-C. Sun, J. M. Lawther, and W. B. Banks, J. Agric. Food Chem., 44, 3965 (1996).

8. A. Scalbert, B. Monties, E. Guittet, and J. Y. Lallemand, Holzforschung, 40, 119 (1986)

9. T. Kondo, T. Ohshita, and T. Kyuma, Anim. Feed Sci. Technol., 39, 253 (1992).

10. A. F. Gogotov, T. I. Makovskaya, and V. A. Babkin, Russian J. Appl. Chem., 69, 776 (1996).

11. J. G. Buta, F. Zadrazil, and G. C. Galletti, J. Agric. Food Chem., 37, 1382 (1989).

12. T. Kondo, T. Watanabe, T. Ohshita, and T. Kyuma, J. Sci. Food Agric., 68, 383 (1995).

13. D. S. Himmelsbach and F. E. Barton II, J. Agric. Food Chem., 28, 1203 (1980).

14. H. H. Nimz, D. Robert, and O. Faix, Holzforschung, 35, 16 (1981).

15. X.-Q. Pan, D. Lachenal, V. Neirinck, and D. Robert, J. Wood Chem. Technol., 14, 483 (1994).

16. T. Imamura, T. Watanable, M. Kuwahara, and T. Koshijima, Phytochemistry, 37, 1165 (1994).

17. C. P. Neto, D. Evtuguin, and A. Robert, J. Wood Chem. Technol., 14, 383 (1994). 